\title{
Genetic management of infectious diseases: a heterogeneous epidemio-genetic model illustrated with $S$. aureus mastitis
}

\author{
Johann C. DETILLEUX* \\ Quantitative Genetics Group, Department of Animal Production, \\ Faculty of Veterinary Medicine, University of Liège, Liège, Belgium
}

(Received 7 October 2004; accepted 27 January 2005)

\begin{abstract}
Given that individuals are genetically heterogeneous in their degree of resistance to infection, a model is proposed to formulate appropriate choices that will limit the spread of an infectious disease. The model is illustrated with data on $S$. aureus mastitis and is based on parameters characterizing the spread of the disease (contact rate, probability of infection after contact, and rate of recovery after infection), the demography (replacement and culling rates) and the genetic composition (degree of relationship and heritability of the disease trait) of the animal population. To decrease infection pressure, it is possible to apply non-genetic procedures that increase the culling (e.g., culling of chronically infected cows) and recovery (e.g., antibiotic therapy) rates of infected cows. But the contribution of the paper is to show that genetic management of infectious disease is also theoretically possible as a control measure complementary to non-genetic actions. Indeed, the probability for an uninfected individual to become infected after contact with an infected one is partially related to their degree of kinship: the more closely they are related, the more likely they are to share identical genes like those associated to the non-resistance to infection. Different prospective genetic management procedures are proposed to decrease the contact rate between infected and uninfected relatives and keep the number of secondary cases generated by one infected animal below 1 .
\end{abstract}

infectious disease resistance / heterogeneous SIS model / genetic management / mastitis

\section{INTRODUCTION}

The distribution of an infectious disease over an animal population and its evolution through time are the results of the dynamic interactions of the host and pathogen systems. To design successful disease-control strategies, it is important to understand what are the most important processes, and how they combine to characterize the dynamics of the disease spread. Mathematical

*Corresponding author: jdetilleux@ulg.ac.be 
models are indispensable when infectious disease data arise from observing complex naturally occurring phenomena. In the mathematical approach, the main biological interactions between hosts, pathogens, and between hosts and pathogens are represented in the form of mathematical functions specified by parameters which quantify the relative strengths of interactions or the rates at which processes evolve.

Various types of epidemic models have been formulated depending upon the characteristic of the infection [5,7]. Among others, the SIS model is appropriate for bacterial infections for which no permanent immunity occurs after recovery. The initials SIS refer to the movement of a typical animal through the two states of the disease: susceptible and infectious. An animal in the state $S$ is uninfected but susceptible to become infected with the disease upon exposure to the contagious agent. Upon infection, it enters the state $I$ and remains in it until recovery to the $S$ state. The rate at which $I$ individuals transmit infection to the $S$ ones is a function of the contact rate between individuals and the probability that any one contact will transmit infection. Given a constant infectious dose (same infectivity for all $I$ animals), this probability is proportional to the non-resistance genotype of the $S$ animals. One must also consider that animals enter and leave the herd independently of their infection status so the demography of the herd may change across time.

Both, deterministic and stochastic modeling approaches exist. Deterministic SIS models are based on ordinary differential equations and capture the essential relationships among the different components. The state of the deterministic system is exactly predictable in contrast to stochastic models in which the state of the system can take a range of values, each with a particular probability of occurring.

Usually, SIS models treat populations as homogeneous in the sense that any $I$ animal is equally likely to infect any $S$ animal and all $S$ animals are equally susceptible to infection by any $I$ animal. While this assumption is an obvious starting point for developing any general theory, it must be recognized that animals are more or less resistant to a same infective dose because of genetic (e.g., innate resistance or tolerance) and non-genetic (e.g., age, sex, or immune status) differences. It seems likely that the genetic factor behind resistance to infectious disease is a combination of a number of genes, each having a small contribution to the risk of disease. Under this assumption, genetic variances and heritability are familiar measures of the degree of genetic determination.

Those measures are closely linked to the relative recurrence risk ratio, i.e., the ratio of the risk of disease in individuals with an affected relative to the risk 
of disease in the general population $[18,24]$. Indeed, relatives sharing genes in common and infected $(I)$ individuals are intrinsically non-resistant. Then, an $I$ individual shares genes with its relatives, genes that have contributed to its nonresistance. Several authors have discussed the effects of host heterogeneity on the ability of an infection to establish itself in a population [4, 21, 30,32] but none have considered the role of the genetic relationship between relatives on the rate of transmission of the infection.

In this paper, homogeneous deterministic and stochastic SIS models were extended in order to investigate the impact of host genetic heterogeneity on the spread of a bacterial infectious disease, such as $S$. aureus bovine mastitis. Model parameters were derived from the literature on $S$. aureus quarter infection and on culling strategies in dairy cattle.

\section{MATERIALS AND METHODS}

Let a population of density $N$ be constituted of $S$ susceptible individuals and $I$ infected ones mixing altogether uniformly, with $S+I=N$. The disease is assumed to be transmitted only by contact between hosts. Among all contact-pairs between infected and susceptible individuals, a proportion $p_{i}$ is between relatives sharing the same $i$ th degree of additive genetic relationship, with $i=1,2, \ldots g$. The initial conditions $(t=0)$ are specified by $S=S_{0}$ and $I=I_{0}$.

\subsection{The deterministic model}

The deterministic form of the SIS model is:

$$
\begin{gathered}
\mathrm{d} S / \mathrm{d} t=\Delta-\mu S+\gamma I-\Sigma_{i} \lambda_{i} p_{i} k[S I] \\
\mathrm{d} I / \mathrm{d} t=\Sigma_{i} \lambda_{i} p_{i} k[S I]-(\gamma+\mu+\varepsilon) I \\
\mathrm{~d} N / \mathrm{d} t=\Delta-\mu N-\varepsilon I
\end{gathered}
$$

where $\Delta$ is the constant replacement rate, $\mu$ is the per-capita natural culling rate, $\gamma$ is the per-capita recovery rate, $\varepsilon$ is the per-capita culling rate due to the infection, $k$ is the per-capita contact rate between individuals, $\lambda_{i}$ is the probability that any one contact will transmit infection, and $[S I]$ is the number of contact-pairs between infected and susceptible individuals (Fig. 1).

Contacts relate to all routes by which the disease could be spread from one animal to another. Individuals are assumed to interact with the same number of other individuals, chosen uniformly and at random within the population 


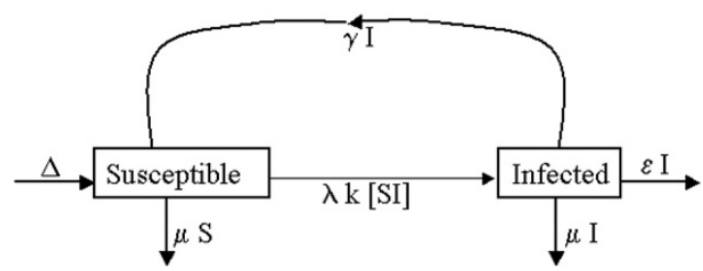

Figure 1. Representation of the model for one particular group of relatives: $\Delta$ is the constant replacement rate, $\mu$ is the per-capita natural culling rate, $\gamma$ is the per-capita recovery rate, $\varepsilon$ is the per-capita culling rate due to the infection, $k$ is the per-capita contact rate between individuals, $\lambda$ is the probability that any one contact will transmit infection, and [SI] is the number of contact-pairs between infected and susceptible individuals.

(assumption of uniform mixing: $[S I]=S I$ ). It is also assumed that the contact rate increases linearly with the density of individuals (frequency-dependence) in contrast with the principle of mass action (density-dependence) [3]. The parameter $\lambda_{i}$ is a measure of the susceptibility of an individual to infection upon contact with the relative of the $i$ th degree and is a function of the degree of additive genetic relationship $\left(a_{i}\right)$ between individuals sharing the $i$ th degree of additive genetic relationship, the heritability of the resistance to infection $\left(h^{2}\right)$, and the average population transmission probability $\left(\lambda_{0}\right): \lambda_{i}=h^{2}\left(1-\lambda_{0}\right) a_{i}+\lambda_{0}$ (details in Appendix A).

\subsection{The stochastic model}

In the stochastic framework, the spread of an SIS infectious disease is modeled as a Markovian continuous-time model [11]. The infinitesimal transition probabilities in the interval $(t, t+\mathrm{d} t)$ are defined by:

$$
\begin{gathered}
\operatorname{Pr}\left[(S, I)_{t+\mathrm{d} t}=(s+1, i) \mid(S, I)_{t}=(s, i)\right] \sim \Delta \mathrm{d} t \\
\operatorname{Pr}\left[(S, I)_{t+\mathrm{d} t}=(s-1, i) \mid(S, I)_{t}=(s, i)\right] \sim \mu s \mathrm{~d} t \\
\operatorname{Pr}\left[(S, I)_{t+\mathrm{d} t}=(s, i-1) \mid(S, I)_{t}=(s, i)\right] \sim(\mu+\varepsilon) i \mathrm{~d} t \\
\operatorname{Pr}\left[(S, I)_{t+\mathrm{d} t}=(s+1, i-1) \mid(S, I)_{t}=(s, i)\right] \sim \gamma i \mathrm{~d} t \\
\operatorname{Pr}\left[(S, I)_{t+\mathrm{d} t}=(s-1, i+1) \mid(S, I)_{t}=(s, i)\right] \sim \sum_{i} \lambda_{i} k p_{i} s i \mathrm{~d} t
\end{gathered}
$$

where $\Delta, \mu, \varepsilon, \gamma, \lambda$ and $k$ have the same meanings as in the deterministic model. 
Table I. Parameters for a model that represents the dynamics of $S$. aureus infections in a population of udder quarters. All rates and parameters are expressed as the number of events per quarter-day at risk.

\begin{tabular}{|c|c|c|c|}
\hline Symbols & Parameter & Symbols and values & References \\
\hline$\lambda_{0}$ & Transmission rate & 0.3 to $4.6 \times 10^{-2}$ & Lam et al., 1996 \\
\hline \multirow[t]{2}{*}{$\lambda_{0}$} & Transmission rate & 0.7 to $4.2 \times 10^{-2}$ & Zadoks et al., 2004 \\
\hline & $\begin{array}{l}\text { Average duration of } \\
\text { infectiousness }\end{array}$ & $\begin{array}{l}170.8(\mathrm{SD}=115.7) \\
\text { days }\end{array}$ & Lam et al., 1996 \\
\hline$\gamma$ & $\begin{array}{l}\text { Cure rate for } \\
\text { untreated infections }\end{array}$ & 0 to $15.7 \times 10^{-3}$ & Zadoks et al., 2004 \\
\hline$\gamma$ & $\begin{array}{l}\text { Cure rate for treated } \\
\text { infections }\end{array}$ & 1.3 to $36.5 \times 10^{-3}$ & Zadoks et al., 2004 \\
\hline \multirow[t]{2}{*}{$\gamma$} & $\begin{array}{l}\text { Culling rate for } \\
\text { heifers with mastitis } \\
\text { from } 30 \text { days before } \\
\text { calving }\end{array}$ & $\begin{array}{l}\text { to } 120 \mathrm{~d} \text { after calv- } \\
\text { ing: } 19.9 \% \\
\text { to } 300 \mathrm{~d} \text { after calv- } \\
\text { ing: } 33.8 \%\end{array}$ & $\begin{array}{l}\text { Heringstad et al., } \\
2003\end{array}$ \\
\hline & $\begin{array}{l}\text { Average age at } \\
\text { culling for mastitis }\end{array}$ & 1200 days & $\begin{array}{l}\text { Van Doormaal and } \\
\text { Brand, } 2002\end{array}$ \\
\hline \multirow[t]{2}{*}{$\varepsilon$} & $\begin{array}{l}\text { Mastitis extra } \\
\text { culling rate }\end{array}$ & 1.2 to $53.5 \times 10^{-3}$ & Zadoks et al., 2004 \\
\hline & $\begin{array}{l}\text { Average age at } \\
\text { culling in healthy } \\
\text { Holstein }\end{array}$ & 2056 days & $\begin{array}{l}\text { Van Doormaal and } \\
\text { Brand, } 2002\end{array}$ \\
\hline$\mu$ & $\begin{array}{l}\text { Culling rate (non } \\
\text { mastitis related) }\end{array}$ & 0.6 to $1.0 \times 10^{-3}$ & Zadoks et al., 2004 \\
\hline$\mu$ & $\begin{array}{l}\text { Culling rate for } \\
\text { heifers from } 30 \text { days } \\
\text { before calving }\end{array}$ & $\begin{array}{l}\text { to } 120 \mathrm{~d} \text { after } \\
\text { calving: } 13.6 \% \\
\text { to } 300 \mathrm{~d} \text { after } \\
\text { calving: } 29.2 \%\end{array}$ & $\begin{array}{l}\text { Heringstad et al., } \\
2003\end{array}$ \\
\hline
\end{tabular}

\subsection{Staph. aureus intra-mammary infection}

Deterministic and stochastic models were illustrated by modeling bovine S. aureus mastitis progression in a dairy herd. The sampling unit was the individual quarter. Among all possible contact-pairs between infected and susceptible quarters, a proportion $p_{i}(i=0,1,2,3,4)$ was between related individuals with an additive coefficient of relationship $a_{i}=0,1 / 2,1 / 2^{2}, 1 / 2^{3}$, and $1 / 24$, respectively. Default values for the parameters were derived from the literature on culling strategies in heifers and on $S$. aureus quarter infection (Tab. I). The units for rates and parameters are the number of events per 
quarter-day at risk $\left(\mathrm{QDR}^{-1}\right)$. Some parameters were derived from the available information (e.g., inverse relation between rate and duration) while others were provided directly by Lam et al. [17] and Zadoks et al. [38]. The replacement rate was set at $\Delta / \mu$ to insure the initial disease-free equilibrium. Since no information was found on the average number of contacts made by a quarter per unit of time, we assumed it was directly proportional to the number of quarters initially present in each group. There was a control program against $S$. aureus mastitis in 'controlled' herds ( $\left.\gamma=0.015 \mathrm{QDR}^{-1}, \varepsilon=0.025 \mathrm{QDR}^{-1}\right)$ but not in 'uncontrolled' herds ( $\left.\gamma=0.006 \mathrm{QDR}^{-1}, \varepsilon=0.001 \mathrm{QDR}^{-1}\right)$ in.

\subsection{Model simulation and interrogation}

The system of deterministic equations was analyzed with the MODEL procedure $\left(\mathrm{SAS}{ }^{\circledR}, 1999\right)$ and the Gillespie algorithm (first reaction method) was selected for the stochastic simulation. This discrete-event simulation technique makes time steps of variable length, based on the transition probabilities and densities of susceptible and infectious individuals. In each of the 3000 iterations, random numbers are generated to determine the time and the type of the next transition. Upon the execution of the selected transition, the populations are altered accordingly and the process is repeated [12].

The prevalence $\left(P_{t}\right)$, i.e. the proportion of infected quarters at different time interval $(t)$, was computed from both deterministic and stochastic models, for $t \leq 5000$ days. In the stochastic approach, $P_{t}$ was averaged over the 3000 iterations. The reproductive number $\left(R_{0}\right)$, i.e., the average number of new infective quarters produced by one infective during the mean (death-adjusted) infective period [16], and the endemic prevalence $\left(P^{*}\right)$ were obtained as results of the numerical stability analyses (details in Appendix B) of the deterministic model. The probability $\left(P_{\text {epi }}\right)$ that a major epidemic will occur was determined as the number of stochastic simulations with more than 1 infected quarter for at least 5000 days over the total number of simulations. The proportion of permissible mixtures of relatives $\left(P_{\text {combi }}\right)$ was computed as the number of combinations of relatives leading to $R_{0}$ below 1 divided by the total number of combinations $(n=981)$ in herds with $a_{i}=0,1 / 2,1 / 2^{2}, 1 / 2^{3}$, and $1 / 2^{4}$. It is the proportion of relatives of any degree for which the epidemic is jugulated.

The models were implemented by introducing a single infected quarter-cow in the herd, given the default values for the parameters characterizing the infection $(\gamma, \varepsilon)$ and the demographic $(\Delta, \mu)$ and genetic $\left(\lambda_{0}, h^{2}, a_{i}\right)$ makeup of the population. In the first genetic makeup (Structure 1), $p_{i}=0.2$ for $i=0,1$, $2,3,4$. Under Structure 2, $p_{0}$ varied from 0 to $100 \%$ and $p_{i}=\left(1-p_{0}\right) / 4$ for 
$i=1,2,3,4$. Sensitivity analyses were conducted under this structure by assigning the lowest and highest values for $\gamma$ and $\varepsilon$ (Tab. I) and by conveying $h^{2}$ for resistance to infection at 5 and $10 \%$. Finally, in order to compute $P_{\text {combi }}$, $p_{i}$ was set to vary from 0 to $100 \%$ by increment of $10 \%$ for $i=0,1,2,3,4$ with the restriction that $\Sigma p_{i}=1$ (Structure 3).

\section{RESULTS}

Given the information collected in Table I, the natural culling and mastitis transmission rates were set at $\mu=7.10^{-4} \mathrm{QDR}^{-1}$ and $\lambda_{0}=2.10^{-2} \mathrm{QDR}^{-1}$, respectively. Under the genetic Structure 1 and for $h^{2}=5 \%, R_{0}=3.74$ in uncontrolled and $R_{0}=0.71$ in controlled herds. The corresponding deterministic and stochastic values for $P_{t}$ are shown in Figure 2 for uncontrolled herds.

The prevalence $P_{t}$ increased up to $48.53 \%$ and $77.2 \%$ in the stochastic and deterministic methods, respectively. After the peak, the deterministic $P_{t}$ decreased to reach an endemic value $\left(P^{*}\right)$ of $50 \%$, as expected from the numerical analyses (Appendix B). The stochastic prevalence $P_{t}$ equilibrated at $P^{*}=32 \%$ and the probability of a major epidemic was very high, with $P_{\text {epi }}=99.97 \%$. In controlled herds, $R_{0}$ was below 1 and $P_{t}$ went to 0 (results not shown).

The results of the sensitivity analyses are shown in Table II for $R_{0}>1$.

The results are not shown for $R_{0}<1$, because $P_{t}=0$ for all $t$. The lowest $R_{0}\left(R_{0}=0.22\right)$ was obtained when $p_{0}=1$ (Structure 2$)$, with $\varepsilon=0.05 \mathrm{QDR}^{-1}$ and $\gamma=0.04 \mathrm{QDR}^{-1}$. The highest $R_{0}\left(R_{0}=15.69\right)$ was achieved for mastitis culling $(\varepsilon)$ and recovery $(\gamma)$ rates of $0.001 \mathrm{QDR}^{-1}$ and $p_{0}=0$. For fixed values of $\gamma$ and $\varepsilon, R_{0}$ decreased twice as fast per percent increase in $p_{0}$ when $h^{2}=10 \%$ than $h^{2}=5 \%$ (Fig. 3). The declines in $R_{0}$ were associated to a decrease in $P^{*}$, $P_{e p i}$, and in the maximum value for $P_{t}$.

In Figure 4 , the proportions of mixture of relatives giving $R_{0}$ below 1 $\left(P_{\text {combi }}\right)$ are shown for controlled herds, $h^{2}=0$ to $100 \%$, and $\lambda_{0}=0.005$ and $0.02 \mathrm{QDR}^{-1}$. Although $R_{0}$ values augmented with increasing $h^{2}$, they remained below one for several different mixtures of relatives: $R_{0}$ was below 1 for more than $10 \%$ of all possible contact-pairs between relatives as long as $h^{2} \leq 0.3$. However, no combination of relatives could lower $R_{0}$ below 1 when $\gamma=0.006 \mathrm{QDR}^{-1}$ and $\varepsilon=0.001 \mathrm{QDR}^{-1}$ (uncontrolled herds). 


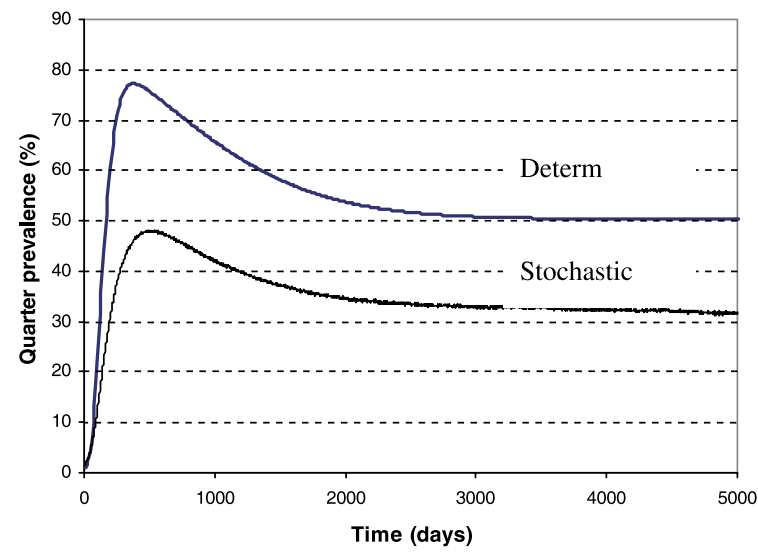

Figure 2. Typical proportion of infected quarters estimated with deterministic and stochastic methods in herds for which the reproductive ratio $R_{0}=3.74$.

Table II. Estimates of reproductive number $\left(R_{0}\right)$, endemic prevalence $\left(P^{*}\right)$, maximum prevalence under the stochastic $\left(P_{\max }^{S}\right)$ and deterministic $\left(P_{\max }^{D}\right)$ models, and probability $\left(P_{e p i}\right)$ that a major epidemic will occur. Estimates were computed for different values for $h^{2}$, culling rate $(\varepsilon)$ for mastitis, mastitis recovery rate $(\gamma)$, and proportion of contact-pairs between infected and susceptible quarters that are between unrelated individuals $\left(p_{0}\right)$. Only values for $R_{0}>1$ are reported.

\begin{tabular}{llrlrlllr}
\hline$h^{2}$ & $\varepsilon$ & \multicolumn{1}{c}{$p_{0}$} & $\gamma$ & \multicolumn{1}{c}{$R_{0}$} & $P^{*}(\%)$ & $P_{\max }^{D}(\%)$ & $P_{\max }^{S}(\%)$ & $P_{e p i}(\%)$ \\
\hline 0.10 & 0.001 & 0 & 0.001 & 15.69 & 84.00 & 96.04 & 86.51 & 99.97 \\
0.10 & 0.001 & 0.5 & 0.001 & 11.50 & 77.86 & 93.72 & 79.43 & 99.97 \\
0.10 & 0.001 & 1.0 & 0.001 & 7.30 & 72.19 & 91.99 & 75.74 & 85.70 \\
0.05 & 0.001 & 0 & 0.001 & 11.50 & 80.16 & 94.84 & 83.01 & 99.97 \\
0.05 & 0.001 & 0.5 & 0.001 & 9.40 & 76.07 & 93.24 & 78.09 & 99.97 \\
0.05 & 0.001 & 1.0 & 0.001 & 7.30 & 72.19 & 91.99 & 77.04 & 86.63 \\
0.10 & 0.001 & 0 & 0.04 & 1.01 & 4.81 & 19.51 & 7.25 & 36.67 \\
0.10 & 0.01 & 0 & 0.001 & 3.62 & 12.45 & 70.01 & 32.21 & 0 \\
0.10 & 0.01 & 0.5 & 0.001 & 2.65 & 7.29 & 45.35 & 16.67 & 0 \\
0.10 & 0.01 & 1.0 & 0.001 & 1.69 & 4.29 & 40.75 & 10.26 & 0 \\
0.05 & 0.01 & 0 & 0.001 & 2.65 & 8.91 & 60.79 & 21.74 & 0 \\
0.05 & 0.01 & 0.5 & 0.001 & 2.17 & 6.21 & 45.59 & 13.68 & 0 \\
0.05 & 0.01 & 1.0 & 0.001 & 1.68 & 4.29 & 40.75 & 9.29 & 0 \\
\hline
\end{tabular}

\section{DISCUSSION}

\subsection{The reproductive number $\left(R_{0}\right)$}

The goals of this paper were to determine under which conditions an infectious disease will spread in a genetically heterogeneous population and how to incorporate genetic elements into the management of such a disease, both 

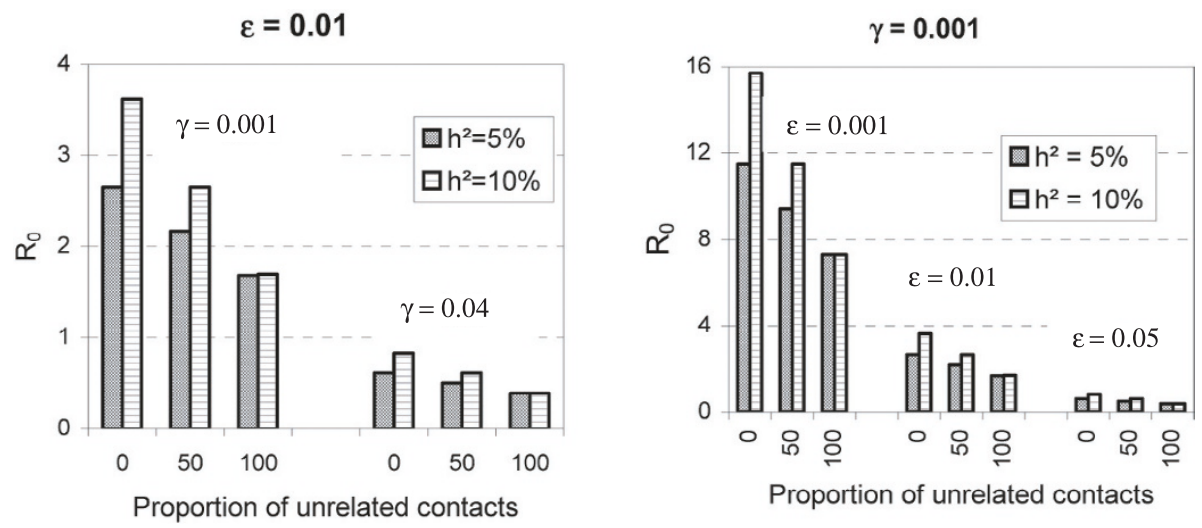

Figure 3. Reproductive number $\left(R_{0}\right)$ for different recovery $(\gamma)$ and mastitis culling $(\varepsilon)$ rates when the proportion of contact-pairs between infected and susceptible quarters that are between unrelated individuals increased from 0 to $100 \%$.

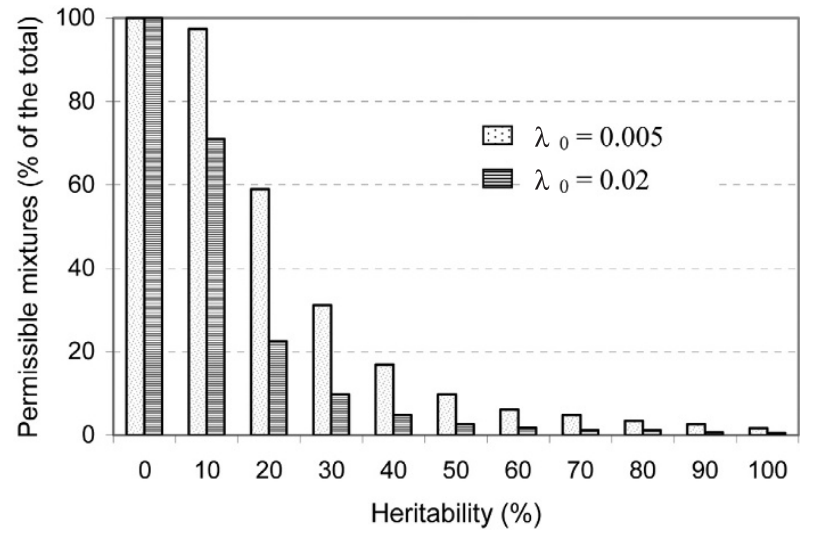

Figure 4. Proportions of mixtures of relatives leading to $R_{0}<1$ in herds under non-genetic management control of $S$. aureus mastitis when the average transmission rate $\left(\lambda_{0}\right)$ varies from 0.005 to 0.02 per quarter-day at risk.

under the assumptions of the SIS model. To reach such goals, it was necessary to compute $R_{0}$ because, when $R_{0}$ is higher than 1 , each infected individual is infecting more than one other individual, the disease can go to an endemic level and control strategies are usually implemented to lower the disease prevalence [10]. Conversely, the epidemic dies out when $R_{0}$ is lower than 1 [1], as illustrated in our mastitis example, in which $R_{0}<1$ and $P_{t}=0$ for all $t$ when herds were under management control against Staph. aureus mastitis.

Under the suggested genetically heterogeneous SIS model, the formula for $R_{0}$ included genetic $\left(h^{2}, a_{i}\right)$ and non-genetic $\left(\lambda_{0}, \gamma, \mu, \varepsilon, k\right)$ components, plus a term $[\Delta / \mu]$ that symbolizes the demographic changes in the population:

$$
R_{0}=\left[\left(\Sigma_{i} \lambda_{i} p_{i} k\right)(\Delta / \mu) /(\gamma+\mu+\varepsilon)\right]
$$


for $i=1$ to $g$. In this equation, the term $\left[k \lambda_{0} /(\gamma+\mu+\varepsilon)\right]$ represents the reproductive number for a disease transmitted strictly non-genetically $\left(h^{2}=0\right)$ in a closed population $(\Delta=\mu)$, as shown by Anderson and May [1]. If the transmission of the infectious disease is strictly genetic $\left(\lambda_{0}=0\right)$, $R_{0}=[1 /(\gamma+\mu+\varepsilon)]\left(h^{2} \Sigma_{i} p_{i} a_{i}\right)$, which is the relative recurrence risk of disease ( $K_{R}$ as defined by Risch et al. [24] during the mean death-adjusted infective period $1 /(\gamma+\mu+\varepsilon)$.

\subsection{Non-genetic management of infectious diseases}

To lower $R_{0}$ below 1 , it is possible to apply non-genetic procedures that increase the culling $(\varepsilon)$ and recovery $(\gamma)$ rates of infected cows. Indeed, culling of chronically infected cows, dry cow therapy and antibiotic treatment are recommended in the control of $S$. aureus infection [13,22]. This was exemplified with the lower $R_{0}$ in controlled $\left(R_{0}=0.71\right)$ than uncontrolled $\left(R_{0}=3.74\right)$ herds under the genetic Structure 1. In Figure 3 and Table II, one can also appreciate the effects of $\gamma$ and $\varepsilon$ on $R_{0}$ for different proportions of unrelated contact-pairs. Yet, in this paper, we will focus on genetic management procedures, acknowledging that the impact of genetic procedures on $R_{0}$ is weighted by all non-genetic factors characterizing the dynamics of the disease. This dependency may be related to the well-known effects of genotype by environment interaction on the risk for many complex disease traits. Indeed, particular cows react differently to particular mastitis pathogens found in various proportions in their environments $[8,14,26,33]$.

\subsection{Genetic management of infectious diseases}

A first genetic approach to decrease $R_{0}$ below 1 is to manage the genetic structure of the population such that:

$$
\left.\Sigma p_{i} a_{i}<[\mu(\gamma+\mu+\varepsilon)]-k \Delta \lambda_{0}\right] /\left[k\left(1-\lambda_{0}\right) \Delta h^{2}\right]
$$

for $i=1$ to $g$. Of course, under the assumptions used in this model, the probability of an epidemic will be minimized if the population is composed only of unrelated animals, as illustrated in Table II (lowest $R_{0}$ for $p_{0}=1$ ), but this is not an absolute constraint [4]. If, for example, effective contact-pairs are between unrelated or between relatives of the $i$ th degree $\left(\Sigma p_{i} a_{i}=p_{0} a_{0}+\left(1-p_{0}\right) a_{i}\right)$, the maximum proportion of relatives admissible to keep $R_{0}$ below 1 is:

$$
\left.p_{i}=[\mu(\gamma+\mu+\varepsilon)]-k \Delta \lambda_{0}\right] /\left[k\left(1-\lambda_{0}\right) \Delta a_{i} h^{2}\right]
$$


with $p_{i}=1-p_{0}$. For example, a closed uncontrolled herd $\left(\gamma=0.006 \mathrm{QDR}^{-1}\right.$, $\varepsilon=0.001 \mathrm{QDR}^{-1}$ ) composed exclusively of unrelated and paternal half-sibs should contain less than $25 \%$ of paternal half-sibs to avoid an epidemic if $\lambda_{0}=0.005 \mathrm{QDR}^{-1}$ and $h^{2}=5 \%$. This proportion is higher when $h^{2}$ or $\lambda_{0}$ are small. This is illustrated in Figure 4 where the proportion of combinations of relatives giving a $R_{0}$ lower than 1 is higher when $h^{2}$ values are low to moderate, values characteristic of numerous infectious diseases [2]. In Detilleux et al. [9], $h^{2}$ for presence/absence of minor and major mammary pathogens were close to $10 \%$ while Schukken et al. [28] found $h^{2}$ for severity of the infection (CFU) after experimental challenge with $S$. aureus essentially null.

A second genetic approach to have $R_{0}<1$ would be to select individuals with the lowest probability of being infected $(\lambda)$. So far, current prediction of breeding values for disease traits such as mastitis is based on linear or threshold animal models [19] in which the data vector $\mathbf{y}$ contains a value of 1 if the individual is diseased and 0 if it is not. In its simplest form, the model may be written as:

$$
\mathbf{y}=\mathbf{1} \mu+\mathbf{a}+\mathbf{e}
$$

with $\mu=$ the fixed population mean, $\mathbf{1}=$ vector of 1 , $\mathbf{a}$ and $\mathbf{e}=$ vector of random effects, $\mathbf{a} \sim N\left(0, \mathbf{A} \sigma_{a}^{2}\right), \mathbf{e} \sim N\left(0, \mathbf{I} \sigma_{e}^{2}\right), \mathbf{A}=$ matrix of additive genetic relationship between individuals, $\sigma_{a}^{2}$ and $\sigma_{e}^{2}=$ additive and error variances, respectively. Under these assumptions, the breeding values are associated to the presence of the disease in an individual at a given point in time, not to the probability that the individual is able to resist to the infection. Therefore, a susceptible individual may be considered as resistant, not because it has resisted infection, but because it has not been exposed to the pathogen. The vector of individual probabilities of being infected $(\lambda)$ may be derived from the equation (Appendix A) used to compute the probability that a susceptible cow becomes infected after an effective contact with an infected relative and from the matrix $\mathbf{A}$ of an additive genetic relationship. Indeed,

$$
\lambda=[\mathbf{1}-\mathbf{y}] \otimes \mathbf{A} \mathbf{y} h^{2}\left(1-\lambda_{0}\right)+[\mathbf{1}-\mathbf{y}] \lambda_{0}
$$

Then, $\lambda$ is the vector of $\lambda_{m}(m=1$ to $N)$ with $\lambda_{m}=0$ if the individual is already infected and $\lambda_{m}=\lambda_{0}+h^{2}\left(1-\lambda_{0}\right) \Sigma_{j} a_{j m}$ if the individual is susceptible to becoming infected; $a_{j m}$ is the additive coefficient of relationship between the $m$ th susceptible animal and the $j$ th infected individual, and $\otimes$ is the direct product. Then, $R_{0}$ is less than 1 when

$$
1^{\prime} \lambda<[(\gamma+\mu+\varepsilon) \mu] /[k \Delta] .
$$


A third approach to obtain $R_{0}<1$ would be to allow selective contacts between animals of different genotypes. So far, the per-capita contact rate between individuals was assumed constant and identical for all types of relationship $(k)$. However, contact rates between infected $(j)$ and susceptible $(m)$ individuals $\left(k_{j m}\right)$ could vary. Then,

$$
\left.R_{0}=[\Delta / \mu][1 / \gamma+\mu+\varepsilon)\right]\left[\Sigma_{m} \Sigma_{j} k_{j m} \lambda_{j m}\right]
$$

with $m=1,2, \ldots, S$ and $j=1,2, \ldots, I$. An interesting approach would be to let infected individuals have contact only with susceptible ones that are the least related to them. Indeed, non-resistant individuals are often highly productive due to the unfavorable genetic correlation between production potential and resistance to infection. For example, genetic correlation between mastitis and milk production ranges from 0.2 to 0.5 [6]. By privileging some contacts between infected (non-resistant) and susceptible (low-producer) individuals and limiting others, one could decrease the incidence rate in the population while keeping the advantages of high productivity.

\subsection{Limitations of the $S$. aureus mastitis model}

While modeling the spread of $S$. aureus mastitis, udder quarters instead of heifers were treated as individual units because exposed quarters are the units at risk of infection by $S$. aureus [25]. Infectivity was assumed constant for all infected cow-quarters even if doses of infectious material may vary between quarters and during the course of the disease [37]. Contacts between quarters were assumed to be density-dependent because Staph. aureus is transmitted through direct individual contact [29] and the average number of contacts per quarter and unit of time is not constant. As in Zadoks et al. [38], only 1st lactating cows were considered to minimize the effect of treatment and preventive strategies. The model also assumed no difference between primary and secondary infections nor between clinical and sub-clinical cases although others $[17,37]$ observed different transmission rates for primary and secondary mammary cases. Influence of host genetics was limited to the susceptibility genes but genetics may also affect other model parameters. Nath et al. [21] showed that genes that decrease transmission of infection, increase the latent period, or decrease the recovery period are critical in controlling disease incidence. Producers may also manage cows differently according to their genetic potential. For example, they may preferentially treat the best-producing infected cows and culled the least-producing ones, which will also change the 
dynamics of the disease spread. A final limitation of our model was the assumption of a constant and time independent recovery rate despite the fact that cows differ in their ability to clear an intra-mammary infection [23].

Despite such assumptions, $R_{0}$ found using the default values for the parameters of mastitis were similar to those reported in field studies. Indeed, $R_{0}$ varied from 1.09 to 7.55 in infected quarters during mastitis outbreak [17] and $R_{0}$ varied from 0.4 to 0.75 in Zadoks et al. [38] suggesting that the contagious transmission of Staph. aureus was controlled in those herds. The estimated prevalences were also within the ranges published for the percentages of quarters in primiparous heifers positive for Staph. aureus [35].

\subsection{Deterministic vs. stochastic approaches}

The results obtained from the average of the 3000 individual stochastic simulations can be compared to the deterministic simulation (Fig. 1). The deterministic simulation converged to the steady equilibrium values $\left(P^{*}\right)$ set by the numerical analyses whereas the stochastic simulation fell substantially short, reaching a plateau at value $<P^{*}$ unless stochastic average values were computed only on major epidemics, in which case they tended towards the deterministic results. Such differences between stochastic average values and dynamic equilibrium quantify the effects of chance events on the size and the timing of epidemics. Indeed, repeated simulations of a stochastic process started with identical initial conditions lead to different realizations of the process, with some simulation going to zero [20] which indicated no establishment of infection. On the contrary, homogeneous deterministic SIS models always predict that the disease will become infinitely persistent in a host population of constant size (Appendix B). Therefore, it was unsurprising to observe averages of the stochastic simulation lower than the endemic prevalence of the deterministic approach [31]: the stochastic average values were computed over all simulations, including those leading to non-establishment of infection or epidemics that quickly died out while the deterministic model gives an expected value of major epidemics.

\subsection{Further research}

The model has some limitations and further research is required to explore the economic benefits of genetic and non-genetic procedures and to find the optimum mix of vaccination, quarantine, treatment and genetic management opportunities. Research on components of resistance (host resistance to 
pathogen growth, infectious dose, ...) other than the one considered in this study (i.e., decrease in probability of infection) should also be investigated, as in Nath et al. [21]. Furthermore, the model could include heterogeneity in pathogen species, as suggested by White et al. [36]. Long-term effects of the management strategies on the frequency of resistant genotypes, as in sheep scrapie [32] could also be explored.

\section{REFERENCES}

[1] Anderson R.M., May R.M., Population biology of infections disease, SpringerVerlag, New York, 1982.

[2] Axford R.F.E., Bishop S.C., Nicholas F.W., Owen J.B., Breeding for diseases resistance in farm animals, 2nd edn., CABI Publishing, Oxon, 2000.

[3] Begon M., Bennett R., Bowers G., French N.P., Hazel S.M., Turner J., A clarification of transmission terms in host-microparasite models: numbers, densities and areas. Epidemiol. Infect. 129 (2002) 147-153.

[4] Bishop S.C., MacKenzie K.M., Genetic management strategies for controlling infectious diseases in livestock populations, Genet. Sel. Evol. 35 (2003) S3-S17.

[5] Brauer F., Castillo-Chavez C., Mathematical models in population biology and epidemiology, 1st edn., Springer-Verlag, New York, 2001.

[6] Carlén E., Strandberg E., Roth A., Genetic parameters for clinical mastitis, somatic cell score, and production in the first three lactations of Swedish Holstein cows, J. Dairy Sci. 87 (2004) 3062-3070.

[7] Daley D.J., Gani J., Epidemic modelling: an introduction, Cambridge University Press, Cambridge, 1999.

[8] de Haas Y., Barkema H.W., Schukken Y.H., Veerkamp R.F., Genetic associations for pathogen-specific clinical mastitis and patterns of peaks in somatic cell count, Anim. Sci. 77 (2003) 187-195.

[9] Detilleux J.C., Marcus K., Jr., Freeman A.E., Fox L.K., Kelley D.H., Mastitis of periparturient Holstein cattle: A phenotypic and genetic Study, J. Dairy Sci. 78 (1995) 2285-2293.

[10] Diekmann O., Heesterbeek J.A.P., Metz J.A.J., On the definition and the computation of the basic reproduction ratio $\mathrm{R} 0$, in models for infectious diseases in heterogeneous populations, J. Math. Biol. 28 (1990) 365-382.

[11] Ewens W.J., Grant G.R., Statistical methods in bioinformatics, Springer-Verlag, New York, 2001.

[12] Gillespie D.T., A general method for numerically simulating the stochastic time evolution of coupled chemical reactions, J. Comput. Phys. 22 (1976) 403-434.

[13] Giraudo J.A., Calzolari A., Rampone H., Rampone A., Giraudo A.T., Bogni C., Larriestra A., Nagel R., Field trials of a vaccine against bovine mastitis. 1. Evaluation in Heifers, J. Dairy Sci. 80 (1997) 845-853.

[14] Gröhn Y.T., Wilson D.J., González R.N., Hertl J.A., Schulte H., Bennett G., Schukken Y.H., Effect of pathogen-specific clinical mastitis on milk yield in dairy cows, J. Dairy Sci. 87 (2004) 3358-3374. 
[15] Heringstad B., Rekaya R., Gianola D., Klemetsdal G., Weigel K.A., Bivariate analysis of liability to clinical mastitis and to culling in first-lactation cows, J. Dairy Sci. 86 (2003) 653-660.

[16] Hyman M., Li J., An intuitive formulation for the reproductive number for the spread of diseases in heterogeneous populations, Math. Biosci. 167 (2000) $65-86$.

[17] Lam T.J.G.M., Dejong M.C.M., Schukken Y.H., Brand A., Mathematical modeling to estimate efficacy of postmilking teat disinfection in split-udder trials of dairy cows, J. Dairy Sci. 79 (1996) 62-70.

[18] Lynch M., Walsh B., Genetics and analysis of quantitative traits, 1st edn., Sinauer Associates, Sunderland, 1998.

[19] Mark T., Applied genetic evaluations for production and functional traits in dairy cattle, J. Dairy Sci. 87 (2004) 2641-2652.

[20] Nasell I., Stochastic models of some endemic infections, Math. Biosci. 179 (2002) 1-19.

[21] Nath J., Woolliams A., Bishop S.C., Identifying critical parameters in the dynamics and control of microparasite infection using a stochastic epidemiological model, J. Anim. Sci. 82 (2004) 384-396.

[22] Nickerson C., Owens W.E., Boddie R.L., Mastitis in dairy heifers: Initial studies on prevalence and control, J. Dairy Sci. 78 (1995) 1607-1618.

[23] Owens W.E., Nickerson S.C., Boddie R.L., Tomita G.M., Ray C.H., Prevalence of mastitis in dairy heifers and effectiveness of antibiotic therapy, J. Dairy Sci. 84 (2001) 814-817.

[24] Risch N., Linkage strategies for genetically complex traits. III. The effect of marker polymorphism on analysis of affected relative pairs, Am. J. Hum. Genet. 46 (1990) 242-53.

[25] Roberson J.R., Fox L.K., Hancock D.D., Gay J.M., Besser T.E., Sources of intramammary infections from Staphylococcus aureus in dairy heifers at first parturition, J. Dairy Sci. 81 (1998) 687-693.

[26] Sabour P.M., Gill J.J., Lepp D., Pacan J.C., Ahmed R., Dingwell R., Leslie K., Molecular typing and distribution of Staphylococcus aureus isolates in eastern Canadian dairy herds, J. Clin. Microbiol. 42 (2004) 3449-3455.

[27] SAS $^{\circledR}$ Institute, The Model procedure, Version 8, Cary, North Carolina, 1999.

[28] Schukken Y.H., Mallard B.A., Dekkers J.C.M., Leslie K.E., Stear M.J., Genetic impact on the risk of intramammary infection following Staphylococcus aureus challenge, J. Dairy Sci. 77 (1994) 639-647.

[29] Sommerhäuser J., Kloppert B., Wolter W., Zschöck M., Sobiraj A., The epidemiology of Staphylococcus aureus infections from subclinical mastitis in dairy cows during a control program, Vet. Microbiol. 96 (2003) 91-102.

[30] Springbett A.J., MacKenzie K., Woolliams J.A., Bishop S.C., The contribution of genetic diversity to the spread of infectious diseases in livestock populations, Genetics 165 (2003) 1465-1474.

[31] Srivastava R., You L., Summers J., Yin J., Stochastic vs. deterministic modelling of intracellar viral kinetics, J. Theor. Biol. 218 (2002) 309-321.

[32] Stringer S.M., Hunter N., Wollhouse M.E.J., A mathematical model of the dynamics of scrapie in a sheep flock, Math. Biosci. 153 (1998) 79-98. 
[33] Tollersrud T., Kenny K., Reitz A.J. Jr., Lee J.C., Mammary isolates of Staphylococcus aureus and other Staphylococcus spp. from Europe and the United States, J. Clin. Microbiol. 38 (2000) 2998-3003.

[34] Van Doormaal B., Brand P., Analysis of recorded disposal reasons in canadian Holsteins, Ayrshires and Jerseys, Réseau laitier canadien. http://www.cdn.ca/committees/archives/ Sept2002. [consulted 5 July 2004].

[35] Waage S., Ødegaard A., Lund A., Brattgjerd S., Røthe T., Case-control study of risk factors for clinical mastitis in postpartum dairy heifers, J. Dairy Sci. 84 (2001) 392-399.

[36] White L.J., Evans N.D., Lam T.J., Schukken Y.H., Medley G.F., Godfrey K.R., Chappell M.J., The structural identifiability and parameter estimation of a multispecies model for the transmission of mastitis in dairy cows, Math. Biosci. 174 (2001) 77-90.

[37] Zadoks R.N., Allore H.G., Barkema H.W., Sampimon O.C., Wellenberg G.J., Gröhn Y.T., Schukken Y.H., Cow- and quarter-level risk factors for Streptococcus uberis and Staphylococcus aureus mastitis, J. Dairy Sci. 84 (2001) 2649-2663.

[38] Zadoks R.N., Allore H.G., Haganaars T., Schukken Y.H., A mathematical model of Staphylococcus aureus control in dairy herds, Epidemiol. Infect. 129 (2002) 397-416.

\section{APPENDIX A}

The parameter $\lambda_{i}$ is defined as the probability that a susceptible cow $S_{i}$ becomes infected after an effective contact with an infected relative $I_{i}$ of the $i$ th type. In statistical terms, this susceptibility can be written as $\lambda_{i}=\operatorname{pr}\left(X_{i}=1 \mid Y_{i}=1\right)$ with $X_{i} \sim \operatorname{Bernoulli}\left(N_{i}, \lambda_{0}\right), Y_{i} \sim \operatorname{Bernoulli}\left(N_{i}, \lambda_{0}\right)$, and $N_{i}=$ number of contact-pairs between $S_{i}$ and $I_{i}$. By definition, and for Bernoulli variables, $\operatorname{Cov}\left(X_{i}, Y_{i}\right)=\mathrm{E}\left(X_{i} Y_{i}\right)-\mathrm{E}\left(X_{i}\right) \mathrm{E}\left(Y_{i}\right)$, and $\mathrm{E}\left(X_{i} Y_{i}\right)=\operatorname{pr}\left(X_{i}=1\right.$ and $\left.Y_{i}=1\right)$. Then, $\lambda_{i}=\left[\operatorname{Cov}\left(X_{i}, Y_{i}\right) \mathrm{E}\left(Y_{i}\right)\right]+\mathrm{E}\left(X_{i}\right)$.

Under the assumptions of random mating, free recombination, and gametic phase equilibrium, the covariance between relatives is a function of the additive coefficient of relationship $\left(a_{i}\right)$ between animals, the heritability of the character $\left(h^{2}\right)$ and the phenotypic variance $\left(\sigma_{p}^{2}\right)$. Ignoring dominance and environmental sources of covariance, $\operatorname{Cov}\left(X_{i}, Y_{i}\right) \sim a_{i} h^{2} \sigma_{p}^{2}$ for one locus and

$$
\lambda_{i}=\lambda_{0}+a_{i} h^{2}\left(1-\lambda_{0}\right)
$$

for the ith group of relatives, as found by Risch et al. [24]. 


\section{APPENDIX B}

For the deterministic form of the SIS model:

$$
\begin{aligned}
\mathrm{d} S / \mathrm{d} t & =\Delta-\mu S+\gamma I-\left(\Sigma_{i} \lambda_{i} p_{i} k\right) S I, \\
\mathrm{~d} I / \mathrm{d} t & =\left(\Sigma_{i} \lambda_{i} p_{i} k\right) S I-(\gamma+\mu+\varepsilon) I,
\end{aligned}
$$

there are two equilibrium values. The first is obtained by setting $\mathrm{d} S / \mathrm{d} t=0$ with $I=0$, i.e., in the absence of infectives. In this case, $\mathrm{d} S / \mathrm{d} t=\Delta-\mu S=0$, and $S_{0}=\Delta / \mu$. The second equilibrium is the endemic equilibrium with $S^{*}$ and $I^{*}$. It is computed by setting $\mathrm{d} I / \mathrm{d} t=0$ and $\mathrm{d} S / \mathrm{d} t=0$ with $I>0$. From $\mathrm{d} I / \mathrm{d} t=\left(\Sigma_{i} \lambda_{i} p_{i} k\right) I S-(\gamma+\mu+\varepsilon) I=0$, one gets:

$$
S^{*}=(\gamma+\mu+\varepsilon)\left(\Sigma_{i} \lambda_{i} p_{i} k\right) .
$$

By setting $\mathrm{d} S / \mathrm{d} t=\Delta \mu S+\gamma-\left(\Sigma_{i} \lambda_{i} p_{i} k\right) S I$ to zero, one gets:

$$
I^{*}=\left[\Delta\left(\Sigma_{i} \lambda_{i} p_{i} k\right)-\mu(\gamma+\mu+\varepsilon)\right] /\left[(\mu+\varepsilon)\left(\Sigma_{i} \lambda_{i} p_{i} k\right)\right] .
$$

The endemic prevalence rate is easily obtained as $P^{*}=S^{*} / I^{*}$.

The reproductive number is determined by the dominant eigenvalue of the Jacobian matrix at the disease-free equilibrium [16]:

$$
J\left(S_{0}, 0\right)=\left(\begin{array}{ll}
-\mu & \gamma-\left(\Sigma_{i} \lambda_{i} p_{i} k\right)(\Delta / \mu) \\
0 & \left(\Sigma_{i} \lambda_{i} p_{i} k\right)(\Delta / \mu)-(\gamma+\mu+\varepsilon)
\end{array}\right) .
$$

Then, the two eigenvalues are $-\mu$ and $\left(\Sigma_{i} \lambda_{i} p_{i} k\right)(\Delta / \mu)-(\gamma+\mu+\varepsilon)$. The first eigenvalue is clearly negative and the second one is negative if $\left(\Sigma_{i} \lambda_{i} p_{i} k\right)(\Delta / \mu)<(\gamma+\mu+\varepsilon)$ or if $R_{0}<1$ with

$$
\begin{aligned}
R_{0} & =\left[\left(\Sigma_{i} \lambda_{i} p_{i} k\right)(\Delta / \mu) /(\gamma+\mu+\varepsilon)\right] \\
& =\left(\Delta / \mu S^{*}\right) .
\end{aligned}
$$

When both eigenvalues are negative, the equilibrium is asymptotically stable (Routh-Hurwitz criterion) which implies that a small population of infectives introduced into the system would not cause a persistent infection; the population would return to the disease-free state after some time. Conversely, if $R_{0}>1$ then the equilibrium is unstable and an introduction of infectives will result in an epidemic that subsequently leads to an endemic infection. 